\title{
BMJ Open Percutaneous coronary intervention in patients with acute coronary syndrome in Chinese Military Hospitals, 2011- 2014: a retrospective observational study of a national registry
}

Ren Zhao, Kai Xu, Yi Li, Miaohan Qiu, Yaling Han, the NRCIMH Program

To cite: Zhao R, Xu K, Li Y, et al. Percutaneous coronary intervention in patients with acute coronary syndrome in Chinese Military Hospitals, 2011-2014: a retrospective observational study of a national registry. BMJ Open 2018;8:e023133. doi:10.1136/ bmjopen-2018-023133

- Prepublication history and additional material for this paper are available online. To view these files, please visit the journal online (http://dx.doi org/10.1136/bmjopen-2018023133).

$\mathrm{RZ}$ and $\mathrm{KX}$ contributed equally.

Received 31 March 2018

Revised 9 July 2018

Accepted 30 August 2018

Check for updates

(C) Author(s) (or their employer(s)) 2018. Re-use permitted under CC BY-NC. No commercial re-use. See rights and permissions. Published by BMJ.

Department of Cardiology, General Hospital of Shenyang Military Command, Shenyang, China

Correspondence to Professor Yaling Han; han_yaling@163.com

\section{ABSTRACT}

Objectives Interventional treatment of patients with acute coronary syndrome (ACS) is surging dramatically in China in recent years, whereas nationwide assessments of the quality of percutaneous coronary intervention $(\mathrm{PCl})$ procedural performance and outcomes are scarce. We aimed to provide an updated and real-world overview of the performance of $\mathrm{PCl}$ in patients with ACS since 2011 in China after the China PEACE study from 2001 to 2011. Methods In this cross-sectional study, data were extracted from the National Registry of Cardiovascular Intervention in Military Hospitals database to create a national sample of 144659 patients with ACS undergoing $\mathrm{PCl}$ at 117 military hospitals in all regions of China from calendar years 2011-2014. Patient characteristics, procedural performance, $\mathrm{PCl}$ outcomes and adverse events and temporal changes were analysed.

Results During 2011-2014, patients with ACS undergoing $\mathrm{PCl}$ increased dramatically. Small numbers of high-volume hospitals performed the majority of $\mathrm{PCI}$ procedures. However, only half of these patients were adequately covered and proportions for the use of assisted devices and novel medications were relatively small. Radial artery access was still increasing with time. Primary PCls were performed on $45.4 \%$ ST-segment elevation myocardial infarction patients with $\mathrm{PCl}$ procedures. 3.8\% lesion vessels involve left main artery. Implanted stents, the overall complications and in-hospital mortality were decreasing remarkably.

Conclusions In Chinese military hospitals, interventional resources were limited with great regional disparities, there are still gaps to be filled to better serve patients with ACS. Our findings can serve as an indispensable supplement to a more comprehensive understanding of the practice of contemporary cardiac intervention in China.

\section{INTRODUCTION}

Due to an ageing population and increasing prevalence of cardiovascular risk factors, China is facing an epidemic of acute coronary syndrome (ACS). In China, military hospitals play an indispensible role in providing healthcare service largely to civilian patients
Strengths and limitations of this study

- This is the first nationwide retrospective observational study of the performance of percutaneous coronary intervention $(\mathrm{PCl})$ in patients with acute coronary syndrome (ACS) covering all geographic regions of mainland China.

- The assessment was based on real-world registry data with sequential enrolment from calendar years 2011-2014.

- $\mathrm{PCl}$ outcomes were based on in-hospital data and no follow-up were done to evaluate the long-term improvement of patients with ACS undergoing PCl.

- Although all PCl-capable military hospitals participated in this programme, patient outcomes might be differentially affected by interventionist in hospitals with various volumes of $\mathrm{PCl}$ procedures each year, thus may confound the overall results.

in peacetime, ${ }^{1-5}$ yet their performance of care were underinvestigated. The drastic increase of acute coronary syndrome (ACS) in China has also catalysed the growth of percutaneous coronary intervention (PCI) in quantity. ${ }^{6}$ However, whether the rapid growth of PCI volume has translated into good quality of care for these patients with ACS treated in military hospitals remains unclear. The adoption of emerging technologies varies substantially across different areas of China. The lack of a nationwide comprehensive assessment of interventional practice hampered the improvement of healthcare provided to these patients. Understand these barriers within the healthcare system of China is imperative to implement change.

The China patient-centered evaluative assessment of cardiac event (PEACE) study was a nationally representative, retrospective study of patients undergoing coronary catheterisation and PCI at 55 urban Chinese 
non-military hospitals in calendar years 2001, 2006 and $2011 .^{6}$ This study found that there were notable changes in practice, including use of radial PCI and medicated stents, yet persistent gaps still existed to improve care. ${ }^{6}$ Military hospitals are independently administered by the Joint Logistic Support Center (the former General Logistics Department) of People's Liberation Army (PLA) in China. To facilitate the management of cardiovascular intervention in military hospitals, the Quality Control Center of Intervention for Cardiovascular Diseases was founded in 2009 by the Bureau of Healthcare of the General Logistics Department. ${ }^{7}$ Quality Improvement Initialtives were launched thereafter to standardise the care of acute myocardial infarction nationwide in military hospitals, including the establishment of Chest Pain Center in qualified cardiac centres. ${ }^{8}$ To standardise and monitor the quality of care for patients undergoing PCI procedures, we conducted the National Registry of Cardiovascular Intervention in Military Hospitals (NRCIMH) study. ${ }^{9-11}$ During calendar years 2011-2014, 117 PCI-capable military hospitals in all seven geographical regions of China and 144659 patients with ACS undergoing PCI procedures were included in this study. Patient characteristics, quality of procedural performance, PCI outcomes, and in-hospital adverse events and their temporal changes were analysed over time.

\section{METHODS}

\section{Study design}

This study was a cross-sectional study using a registered dataset. The original data for this study were extracted from the NRCIMH (web access via http://www.xxgjr. com). This database collected social-demographic, medical and interventional data of patients who had cardiovascular disease and underwent cardiac interventions since October 2010 in all military hospitals nationwide that are qualified to perform cardiac catheterization and PCI. ${ }^{9-11}$ Patient demographics, clinical characteristics and treatment patterns during hospitalisation were collected by physicians who were in charge of the patient, and coronary catheterisation or PCI-related information were collected by the responsible operator or technical assistant. Patient data were censored and uploaded into the database by designated medical personnel in each individual hospital. The majority of patients had coronary artery disease and underwent PCI. All participating hospitals accepted the ethics committee approval.

\section{Study population}

Patients with ACS (with definite discharge diagnosis of either ST-segment elevation myocardial infarction (STEMI), non-ST-segment elevation myocardial infarction (NSTEMI) or unstable angina) undergoing interventional procedures in all 117 military hospitals (online table S1) from 1 January 2011 to 31 December 2014 were included in this study. Diagnoses were made according to the China National Guidelines for ACS, ${ }^{12}{ }^{13}$ which are consistent with guidelines in the USA. ${ }^{14} 15$ Due to the large-volume information inputed into this registry, patients with missing data were excluded in specific categorical analyses, including age, gender, region of hospital, access artery, contrast type, lesion vessel and target vessel. For measured categories like artery stenosis and lesion category, their sum exceed the total number of patients enrolled in each study year is because each patient usually had more than one stenosed/lesioned vessel. For the sake of clarity, the sum for each measured variable category was listed in the column of each category unless otherwise specified. Data integrity for each measure category was not less than $91.8 \%$ in this study.

\section{Variables and definitions}

We collected data from a unified registry form abstracted from the original database systems, including baseline characteristics (diagnosis, patient category, age, gender, ethnicity, region of admission hospital, medical history), perioperative characteristics (primary PCI composition, access artery, contrast type, antiplatelet and anticoagulation medications, assisted devices), PCI outcomes (stenosis pre-PCI, lesion category, lesion vessel, target vessel) and adverse outcomes including complication and death both during PCI and post-PCI. Medical histories including histories of myocardial infarction, cerebrovascular disease, peripheral vascular disease, cardiac valve surgery, coronary artery bypass graft (CABG) and PCI were collected by physicians in charge of that patient (mainly via patient's own statement and further verified, if any, by documentation in previous admission notes, discharge diagnoses or corroborating laboratory test results) and were uploaded into the registry database. For the convenience of calculation, anomalous artery, intermediate artery and vessel graft lesion as well as interventions done in these vessels were all merged into the individual categories. In addition, due to a systematic revision of the registry form since 2013, partial data were analysed and summarised in the supplement, including location and Killip classification of myocardial infarction history, assisted device used during 2011-2013, information regarding medical coverage, thrombolysis of STEMI patient, PCI outcomes and stent manufacturer during 2013-2014.

Patients with corrected TIMI frame count values exceeding the thresholds by $>2$ SD for the particular vessel were recognised as having coronary slow flow. ${ }^{16}$ Major bleeding was defined as any intracranial bleeding, absolute haemoglobin decrease of at least $50 \mathrm{~g} / \mathrm{L}$, bleeding resulting in hypovolemic shock or fatal bleeding (bleeding that resulted directly in death within 7 days). Acute/subacute stent thrombosis was defined according to the Academic Research Consortium criteria. ${ }^{17}$ Postoperative myocardial infarction was diagnosed in accordance with the universal definition of type 4 myocardial infarction. ${ }^{18}$ The cause of death was adjudicated as cardiogenic death, PCI-related death or uncertain. 
A

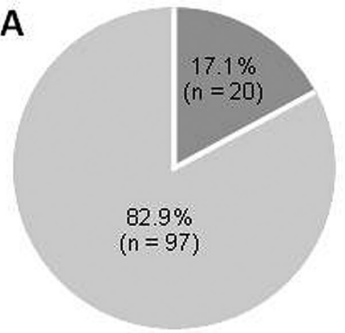

Number of hospitals

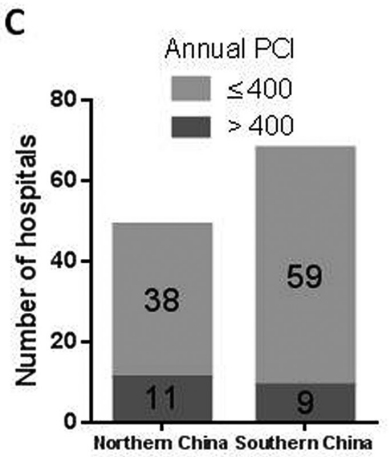

B

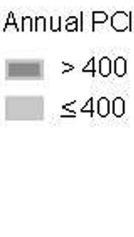

$>400$

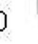

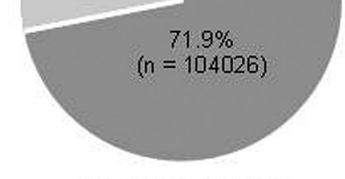

Number of PCls

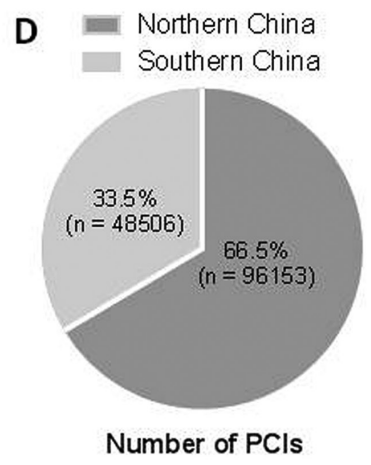

Figure 1 Overall and regional distributions of percutaneous coronary intervention (PCI)-capable military hospitals and $\mathrm{PCl}$ procedures performed. Military hospitals were divided by their annual $\mathrm{PCl}$ volume with a threshold of 400 cases per year (A), as well as further by geographical regions (C); the overall $\mathrm{PCl}$ procedures performed during 2011-2014 were also grouped by annual PCl volumes of hospitals (B) and by regions (D). Northern China include North China, Northwest China and Northeast China, Southern China include South China, East China, Central China and Southwest China.

\section{Statistical analysis}

We used percentages to describe categorical variables and median with IQRs to describe continuous variables unless otherwise specified. $\chi^{2}$ trend tests were used to examine trends across different study years for categorical variables. For the comparison of data between 2013 and 2014, $\chi^{2}$ tests were used for categorical variables and MannWhitney tests for continuous variables with non-normal distribution. We constructed three indicator variables representing years 2012, 2013 and 2014, leaving 2011 as the reference. We did logistic regressions including these indicators for time as key explanatory variables, while adjusting for patients' ACS types (unstable angina, NSTEMI, STEMI), demographics (age and sex), comorbidities (hypertension, hyperlipidemia, diabetes mellitus, chronic obstructive pulmonary disease, current smoking, heart failure, renal failure, under dialysis, prior cerebrovascular disease, prior peripheral vascular disase, prior PCI, prior cardiac valve surgery, prior CABG). The dependent variable was in-hospital death. We also tested the linear trend over time in the models. We report ORs and 95\% CIs from the multilevel logistic regression related to the year indicators. All comparisons were two-sided, with statistical significance defined as $\mathrm{p}<0.05$. Statistical analyses were performed using GraphPad Prism V.6.01 and SAS software V.9.3.

\section{Patient and public involvement}

Patients and public were not involved in this study.

\section{RESULTS}

A total of 144659 patients with ACS undergoing PCI in 117 military hospitals were recruited into this study from 2011 to 2014 , located in all seven geographic regions of mainland China, including North China $(n=25)$, Northwest $(n=14)$, Northeast $(n=10)$, East China $(n=29)$, Southwest $(n=14)$, Central China $(n=12)$ and South China $(n=13)$. Of these, 82 hospitals provided 140374 cases $(97.0 \%)$ across all the study years (online table S1). In brief, only $20(17.1 \%)$ hospitals performed more than 400 PCIs on ACS patients annually (figure 1A), and these hospitals performed $71.9 \%$ PCIs (104 026 cases) during 2011-2014 (figure 1B). Geographically, although the total number of hospitals in Northern China (North China, Northwest, Northeast regions) was less than that in Southern China (South China, East China, Central China and Southwest regions), there were more military hospitals in Northern China performed PCI procedures $>400$ cases per year than those in Southern China (figure 1C), and northern military hospitals performed the majority of PCIs during the study years $(66.5 \%)$ (figure 1D).

Generally, the number of patients with ACS undergoing PCI has increased by $27.8 \%$, while the proportions of most comorbidities of these patients had concordant decrease over time. Hospitals in northern China (North China, Northwest and Northeast) performed the majority of PCIs, with most patients being civilian and with Han ethnicity. There were significant increases in the proportions of patients diagnosed as unstable angina pectoris, of civilian identity, male gender, treated in hospitals in Northeast, East and South China, and significant decreases in the proportions of patients diagnosed as STEMI, treated in hospitals in North China, Northwest and Central China (table 1). During 2013-2014, only half of these patients were covered by urban resident medical service (53.4\%-53.6\%) (online table $\mathrm{S} 2$ ).

The proportion of primary PCI dropped significantly in patients with ACS in all categories. In STEMI patients, the fraction of primary PCI in all PCI performed did not change dramatically $(44.0 \%-47.9 \%$, table 2$)$. There is remarkable increase in the proportion of anterior myocardial infarction and significant decrease in the proportion of cardiac function defined as Killip III/ IV (online table S3). There was more time delay on first medical contact to balloon dilation in 2014 than in 2013 (median 50 vs 40, p<0.01) (online table S4). PCI procedures done through the radial artery had increased markedly from $72 \%$ in 2011 to $90.4 \%$ in 2014 . The use of clopidogrel and GP IIb/IIIa inhibitor dropped significantly. Proportions of novel drugs like ticagrelor and bivalirudin, and of assisted devices such as intra-aortic 


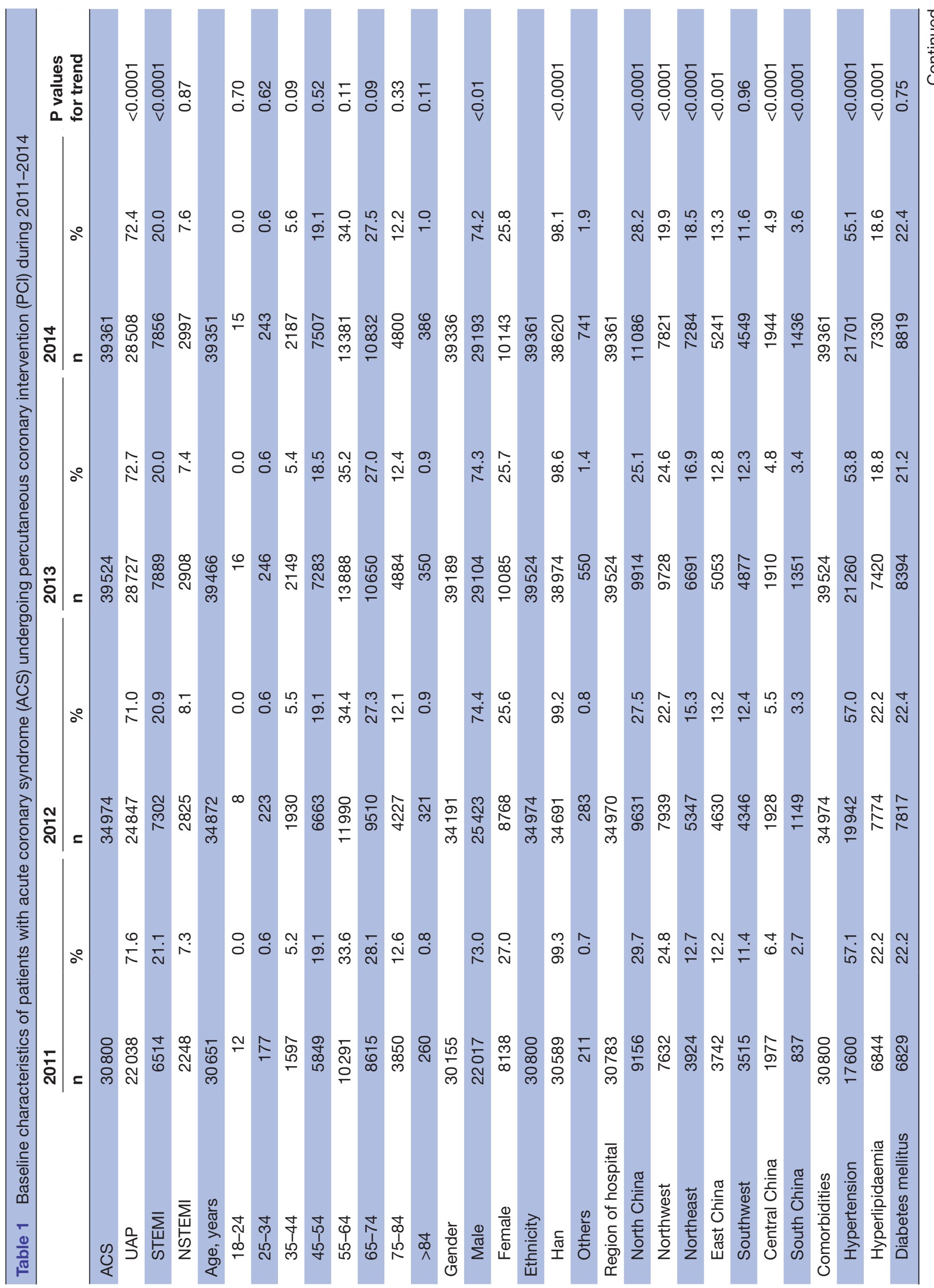




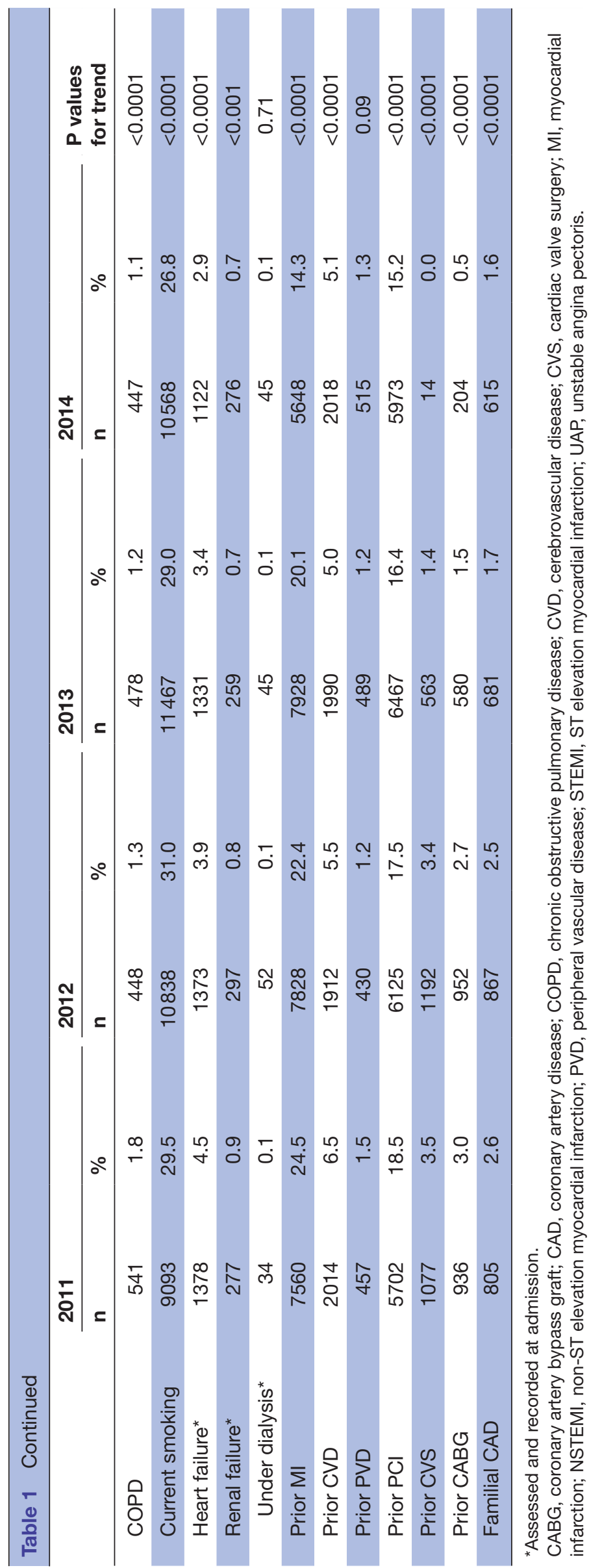


Table 2 Perioperative characteristics of patients with acute coronary syndrome (ACS) undergoing percutaneous coronary intervention (PCl) during 2011-2014

\begin{tabular}{|c|c|c|c|c|c|c|c|c|c|}
\hline & \multicolumn{2}{|l|}{2011} & \multicolumn{2}{|l|}{2012} & \multicolumn{2}{|l|}{2013} & \multicolumn{2}{|l|}{2014} & \multirow{2}{*}{$\begin{array}{l}\mathrm{P} \\
\text { valuesfor } \\
\text { trend }\end{array}$} \\
\hline & $\mathbf{n}$ & $\%$ & $\mathbf{n}$ & $\%$ & $\mathbf{n}$ & $\%$ & $\mathbf{n}$ & $\%$ & \\
\hline $\mathrm{pPCl}$ & 30800 & & 34974 & & 39524 & & 39361 & & \\
\hline Yes & 3689 & 12.0 & 4359 & 12.5 & 4263 & 10.8 & 4211 & 10.7 & $<0.0001$ \\
\hline On STEMI & 2866 & 9.3 & 3499 & 10.0 & 3505 & 8.9 & 3544 & 9.0 & $<0.01$ \\
\hline $\mathrm{pPCl} / \mathrm{PCl}$ & $2866 / 6514$ & 44.0 & $3499 / 7302$ & 47.9 & $3505 / 7889$ & 44.4 & $3544 / 7856$ & 45.1 & 0.78 \\
\hline On NSTEMI & 334 & 1.1 & 372 & 1.1 & 349 & 0.9 & 365 & 0.9 & $<0.01$ \\
\hline On UAP & 489 & 1.6 & 488 & 1.4 & 409 & 1.0 & 302 & 0.8 & $<0.0001$ \\
\hline No & 27111 & 88.0 & 30615 & 87.5 & 35261 & 89.2 & 35150 & 89.3 & \\
\hline Access artery & 30800 & & 34800 & & 39524 & & 39361 & & \\
\hline Radial & 22171 & 72.0 & 28266 & 81.2 & 34520 & 87.3 & 35582 & 90.4 & $<0.0001$ \\
\hline Femoral & 8453 & 27.4 & 6527 & 18.7 & 4803 & 12.2 & 3545 & 9.0 & $<0.0001$ \\
\hline Brachial & 165 & 0.5 & 170 & 0.5 & 187 & 0.5 & 209 & 0.5 & 0.94 \\
\hline Others & 11 & 0.0 & 11 & 0.0 & 14 & 0.0 & 25 & 0.1 & 0.06 \\
\hline Contrast type & 30080 & & 34154 & & 38585 & & 39361 & & \\
\hline Non-ionic & 30027 & 99.8 & 34119 & 99.9 & 38493 & 99.8 & 39198 & 99.6 & $<0.0001$ \\
\hline Iso-osmolar & 10055 & 33.4 & 12988 & 38.0 & 16540 & 42.9 & 20034 & 50.9 & $<0.0001$ \\
\hline Low-osmolar & 19972 & 66.4 & 21131 & 61.9 & 21953 & 56.9 & 19164 & 48.7 & $<0.0001$ \\
\hline Ionic & 53 & 0.2 & 35 & 0.1 & 92 & 0.2 & 163 & 0.4 & $<0.0001$ \\
\hline Antiplatelet & 30800 & & 34974 & & 39524 & & 39361 & & \\
\hline Aspirin & 29459 & 95.6 & 34189 & 97.8 & 38267 & 96.8 & 38547 & 97.9 & $<0.0001$ \\
\hline Clopidogrel & 29486 & 95.7 & 34231 & 97.9 & 37165 & 94.0 & 36122 & 91.8 & $<0.0001$ \\
\hline Ticagrelor & 30 & 0.1 & 13 & 0.0 & 222 & 0.6 & 1299 & 3.3 & $<0.0001$ \\
\hline Ticlopidine & 54 & 0.2 & 50 & 0.1 & 520 & 1.3 & 1202 & 3.1 & $<0.0001$ \\
\hline Cilostazol & 22 & 0.1 & 17 & 0.0 & 23 & 0.1 & 15 & 0.0 & 0.11 \\
\hline GP Ilb/Illa inhibitor & 4670 & 15.2 & 6232 & 17.8 & 6135 & 15.5 & 5099 & 13.0 & $<0.0001$ \\
\hline Anticoagulation & 30800 & & 34974 & & 39524 & & 39361 & & \\
\hline UFH & 18788 & 61.0 & 21343 & 61.0 & 22885 & 57.9 & 24547 & 62.4 & 0.19 \\
\hline LMWH & 9248 & 30.0 & 10398 & 29.7 & 12622 & 31.9 & 12012 & 30.5 & $<0.01$ \\
\hline Fondaparinux & 373 & 1.2 & 939 & 2.7 & 886 & 2.2 & 0 & 0.0 & $<0.0001$ \\
\hline Bivalirudin & 0 & 0.0 & 0 & 0.0 & 93 & 0.2 & 395 & 1.0 & $<0.0001$ \\
\hline IABP & 30800 & & 34974 & & 39524 & & 39361 & & \\
\hline Yes & 450 & 1.5 & 579 & 1.7 & 584 & 1.5 & 432 & 1.1 & $<0.0001$ \\
\hline No & 30350 & 98.5 & 34395 & 98.3 & 38940 & 98.5 & 38929 & 98.9 & \\
\hline IVUS & 30800 & & 34974 & & 39524 & & 39361 & & \\
\hline Yes & 439 & 1.4 & 399 & 1.1 & 383 & 1.0 & 439 & 1.1 & $<0.0001$ \\
\hline No & 30361 & 98.6 & 34575 & 98.9 & 39141 & 99.0 & 38922 & 98.9 & \\
\hline
\end{tabular}

GP IIb/IIla, glycoprotein IIb/IIla; IABP, intra-aortic balloon pump; IVUS, intravascular ultrasound; LMWH, low molecular weight heparin; NSTEMI, non-ST elevation myocardial infarction; pPCI, primary percutaneous coronary intervention; STEMI, ST elevation myocardial infarction; UAP, unstable angina pectoris; UFH, unfractionated heparin.

balloon pump (IABP), intravascular ultrasound (IVUS), optical coherence tomography (OCT) and fractional flow reserve (FFR) measurement, were low in all time periods (table 2, online table S5). In addition, from 2013 to 2014, thrombolysis in patients with STEMI was not altered in terms of performance rate, thrombolytics and time delay from angina to thrombolysis increased remarkably and the success rate dropped significantly as well (online table S6).

Under catheterisation, artery stenosis $>75 \%$ increased significantly in proportions during the study years. Long lesion constitutes approximately one-third of the overall 
lesions, there were increased trends in the proportion of general lesion, total occluded lesion and thrombus lesion, and decreased trends in long lesion, calcified lesion and bifurcation lesion. The proportion of triplevessel lesion significantly decreased, while that of solitary vessel lesion increased dramatically. Under PCI, target vessels were primarily solitary with increased trends in proportions of all arteries, followed by double vessels with decreased proportions. Target vessels involving LM consist $3.4 \%$ to $4.2 \%$ of all PCI procedures. PCI procedures targeting triple vessels had also decreased both in amount and in proportion (table 3). From 2013 to 2014, the mean implanted stent per patient decreased from 1.5 to $1.4(\mathrm{p}<0.01)$ (online table $\mathrm{S} 7)$, the majorities implanted stents were made by domestic companies with a decreased proportion over time (online table S8).

In general, more complications were recorded during PCI than post PCI, and the overall complications were significantly decreased both in amount and in proportion, either during PCI or post-PCI. During PCI procedures, slow flow, serious dissection, acute thrombosis, perforation and cardiac tamponade had markedly decreased. As for complications after PCI, acute/subacute stent thrombosis, organ failure, major bleeding/haematoma, contrast reaction and thromboembolism had decreased trends in proportion during the study years. There were also significantly decreased trends of death both in amount and in proportion, during/after PCI, with the majority of death found after PCI procedures due to cardiogenic triggers (table 4). After adjustment for patient demographic and clinical characteristics in the multilevel logistic regression, the risk of in-hospital mortality also significantly decreased over time (figure 2).

\section{DISCUSSION}

To the best of our knowledge, this is the first large, nationwide study of patients with ACS undergoing PCI in Chinese military hospitals. Compared with contemporary developed country such as the USA, the proportion of hospitals capable of performing PCIs $>400$ cases was substantially low $\left(17.1 \%\right.$ vs $41.5 \%$ in USA).$^{19}$ Accordingly, the application rates of assisted devices were also low, such as IABP $(1.1 \%-1.7 \%)$, temporary pacemaker $(1.9 \%-2.4 \%)$, IVUS $(1.0 \%-1.4 \%)$, OCT $(0.1 \%)$ and FFR measurement $(0.1 \%-0.5 \%)$ as the support is available with experienced interventional cardiologists and skilled support staff in high-volume well-equipped facilities. Out data also suggest great regional disparities of PCI procedures performed on patients with ACS, with patients in the north region of China (North China, Northwest and Northeast) consumed the majority of interventional resources $(65.5 \%-67.2 \%$ of all PCI cases for patients with ACS, table 1). This also reflects pandemic state of unstable coronary artery disease in these regions. ${ }^{20-22}$ In this regard, medical resources shall be prioritised to better serve disparate needs in different regions, especially the north region of China. Furthermore, the healthcare coverage system in contemporary China is also concerning, as during 2013-2014 only 53.4\%-53.6\% patients with ACS were covered under urban resident medical service with high reimbursement rate, while $20.1 \%-22.1 \%$ patients were covered under new rural cooperative medical service with low reimbursement rate, and $16.3 \%-17.2 \%$ patients were uncovered. ${ }^{23-25}$ Given the great economic burdens patients with ACS bear on PCI procedures and medications during hospitalisation and thereafter, ${ }^{26-28}$ the current medical coverage patterns shall be optimised to improve the quality of life for these patients as well as their families. Nevertheless, the overall decreased trends in proportions of comorbidities suggest the effectiveness of cardiovascular-related disease control during 2011-2014 in China.

Primary PCI was performed with high prevalence in hospitals of developed countries. For example, in a recent nationwide Belgian STEMI registry during 20092013, 89.6\% of patients with STEMI underwent primary PCI. ${ }^{29}$ In the US National Cardiovascular Data Registry (NCDR) 2010-2011 report, the primary PCI consisted $84.8 \%$ of all PCI performed for patients with STEMI. ${ }^{30}$ However, the proportion of primary PCI performed on STEMI patients was still very low in this study, and this proportion did not change significantly over time $(44.0 \%$ in 2011 to $45.1 \%$ in 2014). This could be explained by the low proportion of high-volume PCI-capable hospitals in China as these hospitals are well-equipped with experienced interventional cardiologists and skilled support staff, which are all required for the successful implementation of primary PCI. Nevertheless, median time delay of first medical contract (FMC) to balloon dilation for primary PCIs done with patients with STEMI during 2013-2014 were $50 \mathrm{~min}$, which were far below the guideline-recommended threshold of $90 \mathrm{~min} .{ }^{31}$ This important quality improvement might be catalysed by the awareness of the performance metric for participating hospitals as the study demonstrated that patients treated in hospitals that had been enrolled in the D2B Alliance for $>3$ months were significantly more likely to have D2B times of $<90 \mathrm{~min}$ than patients treated in non-enrolled hospitals. ${ }^{32}$ In this regard, the scenario of D2B time in real-world practice might be less satisfying as performance metrics were largely unmonitored. Furthermore, given that time delay of angina onset to FMC was still huge (median $270 \mathrm{~min}$ ), great efforts are still needed to promote broader initiatives at a systems level to reduce total ischaemic time, which was shown as the principal determinant of outcome. ${ }^{33}{ }^{34}$ These efforts might include patient education, improvements in emergent medical service and emergent department care, establishment of networks of non-PCI-capable and PCI-capable hospitals, and work with policymakers to implement healthcare system reform. ${ }^{35-41}$

The current study depicted several notable changes as compared with the former China PEACE study. In their study, Xin Zheng and colleagues reported dramatic increase of the adoption of radial artery access from $3.5 \%$ 
Table 3 percutaneous coronary intervention ( $\mathrm{PCl}$ ) characteristics of patients with acute coronary syndrome (ACS) during 2011-2014

\begin{tabular}{|c|c|c|c|c|c|c|c|c|c|}
\hline & \multicolumn{2}{|l|}{2011} & \multicolumn{2}{|l|}{2012} & \multicolumn{2}{|l|}{2013} & \multicolumn{2}{|l|}{2014} & \multirow{2}{*}{$\begin{array}{l}P \text { values } \\
\text { for trend }\end{array}$} \\
\hline & $\mathrm{n}$ & $\%$ & $\mathrm{n}$ & $\%$ & $\mathbf{n}$ & $\%$ & $\mathrm{n}$ & $\%$ & \\
\hline Artery stenosis (\%) & 39090 & & 42260 & & 46915 & & 46938 & & \\
\hline $75-99$ & 27879 & 71.3 & 31048 & 73.5 & 34976 & 74.6 & 35971 & 76.6 & $<0.0001$ \\
\hline 100 & 7228 & 18.5 & 8642 & 20.4 & 9704 & 20.7 & 9385 & 20.0 & $<0.0001$ \\
\hline $50-75$ & 3557 & 9.1 & 2326 & 5.5 & 2003 & 4.3 & 1540 & 3.3 & $<0.0001$ \\
\hline$<50$ & 426 & 1.1 & 244 & 0.6 & 232 & 0.5 & 42 & 0.1 & $<0.0001$ \\
\hline Lesion category & 38606 & & 41713 & & 46292 & & 46073 & & \\
\hline Long lesion* & 13571 & 35.2 & 14939 & 35.8 & 16375 & 35.4 & 15736 & 34.2 & $<0.001$ \\
\hline General lesion & 12686 & 32.9 & 13036 & 31.3 & 14874 & 32.1 & 15878 & 34.5 & $<0.0001$ \\
\hline Total occluded lesion & 4597 & 11.9 & 5532 & 13.3 & 6058 & 13.1 & 5930 & 12.9 & $<0.001$ \\
\hline Calcified lesion & 3184 & 8.2 & 3006 & 7.2 & 3473 & 7.5 & 2781 & 6.0 & $<0.0001$ \\
\hline Bifurcation lesion & 2545 & 6.6 & 2463 & 5.9 & 2479 & 5.4 & 2891 & 6.3 & $<0.01$ \\
\hline Thrombus lesion & 1782 & 4.6 & 2469 & 5.9 & 2711 & 5.9 & 2549 & 5.5 & $<0.0001$ \\
\hline Small vessel† & 217 & 0.6 & 246 & 0.6 & 277 & 0.6 & 272 & 0.6 & 0.59 \\
\hline Bypass graft lesion & 24 & 0.1 & 22 & 0.1 & 45 & 0.1 & 36 & 0.1 & 0.12 \\
\hline Lesion vesselł & 30457 & & 34800 & & 39427 & & 39295 & & \\
\hline Triple & 12298 & 40.4 & 12803 & 36.8 & 13253 & 33.6 & 12301 & 31.3 & $<0.0001$ \\
\hline Solitary & 8580 & 28.2 & 11567 & 33.2 & 14395 & 36.5 & 14912 & 37.9 & $<0.0001$ \\
\hline LAD & 5397 & 17.7 & 7090 & 20.4 & 8544 & 21.7 & 8599 & 21.9 & $<0.0001$ \\
\hline $\mathrm{RCA}$ & 2147 & 7.0 & 3111 & 8.9 & 3866 & 9.8 & 4222 & 10.7 & $<0.0001$ \\
\hline LCX & 1036 & 3.4 & 1366 & 3.9 & 1985 & 5.0 & 2038 & 5.2 & $<0.0001$ \\
\hline Double & 7308 & 24.0 & 8104 & 23.3 & 9180 & 23.3 & 9374 & 23.9 & 0.84 \\
\hline LAD+RCA & 3694 & 12.1 & 3936 & 11.3 & 4270 & 10.8 & 4285 & 10.9 & $<0.0001$ \\
\hline LAD+LCX & 2558 & 8.4 & 2968 & 8.5 & 3475 & 8.8 & 3554 & 9.0 & $<0.001$ \\
\hline $\mathrm{LCX}+\mathrm{RCA}$ & 1056 & 3.5 & 1200 & 3.4 & 1435 & 3.6 & 1535 & 3.9 & $<0.001$ \\
\hline Triple+LM & 1540 & 5.1 & 1481 & 4.3 & 1638 & 4.2 & 1644 & 4.2 & 0.0001 \\
\hline Double+LM & 489 & 1.6 & 502 & 1.4 & 574 & 1.5 & 593 & 1.5 & 0.41 \\
\hline$L A D+L C X+L M$ & 230 & 0.8 & 247 & 0.7 & 339 & 0.9 & 315 & 0.8 & 0.16 \\
\hline$L A D+R C A+L M$ & 195 & 0.6 & 212 & 0.6 & 198 & 0.5 & 215 & 0.5 & $<0.05$ \\
\hline $\mathrm{LCX}+\mathrm{RCA}+\mathrm{LM}$ & 64 & 0.2 & 43 & 0.1 & 37 & 0.1 & 63 & 0.2 & 0.09 \\
\hline Solitary+LM & 178 & 0.6 & 253 & 0.7 & 300 & 0.8 & 367 & 0.9 & $<0.0001$ \\
\hline LAD+LM & 139 & 0.5 & 197 & 0.6 & 220 & 0.6 & 281 & 0.7 & $<0.0001$ \\
\hline $\mathrm{RCA}+\mathrm{LM}$ & 26 & 0.1 & 37 & 0.1 & 51 & 0.1 & 49 & 0.1 & 0.09 \\
\hline LCX+LM & 13 & 0.0 & 19 & 0.1 & 29 & 0.1 & 37 & 0.1 & $<0.01$ \\
\hline LM & 64 & 0.2 & 90 & 0.3 & 107 & 0.3 & 128 & 0.3 & $<0.01$ \\
\hline Target vesself & 28278 & & 32836 & & 38176 & & 39224 & & \\
\hline Solitary & 20801 & 73.6 & 25513 & 77.7 & 30592 & 80.1 & 31456 & 80.2 & $<0.0001$ \\
\hline LAD & 10735 & 38.0 & 13277 & 40.4 & 15749 & 41.3 & 15960 & 40.7 & $<0.0001$ \\
\hline LCX & 3017 & 10.7 & 3563 & 10.9 & 4665 & 12.2 & 4867 & 12.4 & $<0.0001$ \\
\hline RCA & 7049 & 24.9 & 8673 & 26.4 & 10178 & 26.7 & 10629 & 27.1 & $<0.0001$ \\
\hline Double & 5713 & 20.2 & 5685 & 17.3 & 5906 & 15.5 & 5886 & 15.0 & $<0.0001$ \\
\hline$L A D+L C X$ & 2723 & 9.6 & 2683 & 8.2 & 2865 & 7.5 & 2815 & 7.2 & $<0.0001$ \\
\hline$L A D+R C A$ & 1978 & 7.0 & 1937 & 5.9 & 1904 & 5.0 & 1932 & 4.9 & $<0.0001$ \\
\hline $\mathrm{LCX}+\mathrm{RCA}$ & 1012 & 3.6 & 1065 & 3.2 & 1137 & 3.0 & 1139 & 2.9 & $<0.0001$ \\
\hline
\end{tabular}


Table 3 Continued

\begin{tabular}{|c|c|c|c|c|c|c|c|c|c|}
\hline & \multicolumn{2}{|l|}{2011} & \multicolumn{2}{|l|}{2012} & \multicolumn{2}{|l|}{2013} & \multicolumn{2}{|l|}{2014} & \multirow{2}{*}{$\begin{array}{l}P \text { values } \\
\text { for trend }\end{array}$} \\
\hline & $\mathbf{n}$ & $\%$ & $\mathbf{n}$ & $\%$ & $\mathbf{n}$ & $\%$ & $\mathbf{n}$ & $\%$ & \\
\hline Solitary+LM & 566 & 2.0 & 603 & 1.8 & 690 & 1.8 & 923 & 2.4 & $<0.001$ \\
\hline LAD+LM & 482 & 1.7 & 531 & 1.6 & 600 & 1.6 & 782 & 2.0 & $<0.01$ \\
\hline LCX+LM & 68 & 0.2 & 58 & 0.2 & 71 & 0.2 & 123 & 0.3 & $<0.05$ \\
\hline RCA+LM & 16 & 0.1 & 14 & 0.0 & 19 & 0.0 & 18 & 0.0 & 0.68 \\
\hline Double+LM & 483 & 1.7 & 455 & 1.4 & 462 & 1.2 & 464 & 1.2 & $<0.0001$ \\
\hline$L A D+L C X+L M$ & 405 & 1.4 & 375 & 1.1 & 387 & 1.0 & 382 & 1.0 & $<0.0001$ \\
\hline$L A D+R C A+L M$ & 73 & 0.3 & 69 & 0.2 & 69 & 0.2 & 72 & 0.2 & $<0.05$ \\
\hline$L C X+R C A+L M$ & 5 & 0.0 & 11 & 0.0 & 6 & 0.0 & 10 & 0.0 & 0.92 \\
\hline Triple & 568 & 2.0 & 433 & 1.3 & 354 & 0.9 & 298 & 0.8 & $<0.0001$ \\
\hline LM & 97 & 0.3 & 113 & 0.3 & 153 & 0.4 & 173 & 0.4 & $<0.05$ \\
\hline Triple+LM & 50 & 0.2 & 34 & 0.1 & 19 & 0.0 & 24 & 0.1 & $<0.0001$ \\
\hline
\end{tabular}

${ }^{*}$ Denotes length of lesion $>20 \mathrm{~mm}$.

†Denotes vessel diameter $<2.5 \mathrm{~mm}$.

†Include anomalous artery, intermediate artery and vessel graft.

LAD, left anterior descending artery; LCX, left circumflex artery; LM, left main artery; RCA, right coronary artery.

to $79.0 \%$ in the practice of interventional cardiology in China during 2001-2011. ${ }^{6}$ In this study of patients with ACS, the trend is still rising, with $72.0 \%$ PCI procedures accessed via radial artery in 2011 to $90.4 \%$ in 2014, compared with $10.9 \%$ cases/procedures performed by means of a radial approach in 2011 to $25.2 \%$ in 2014 in the USA (NCDR). Also, the China PEACE-Retrospective CathPCI Study group reported that the proportions of patients who received a glycoprotein IIb/IIIa inhibitor and clopidogrel both increased from 2001 to 2011 in non-military hospitals in China. ${ }^{6}$ Unlike their findings, in our study, the proportions of clopidogrel and glycoprotein IIb/IIIa inhibitor both decreased significantly $(95.7 \%$ to $91.8 \%$ and $15.2 \%$ to $13.0 \%$, respectively), it might suggest different patterns of medications between non-military hospitals and military hospitals in the field of interventional cardiology, or just be a result of rapidly evolved medical practice in all hospitals in contemporary China, possibly due to the emergence of novel P2Y12 inhibitor ticagrelor and novel anticoagulant bivalirudin in China. Meanwhile, operators implanted less stents per patient in 2014 than in 2013 (mean 1.4 vs 1.5), which was also remarkably less than those implanted during 2001-2011 in China PEACE study (mean 1.4 in 2001, 1.7 in 2006 and 1.8 in 2011). ${ }^{6}$ This may be as a result of the enforcement of quality improvement initiatives during 2011-2014 by the Quality Control Center of Intervention for Cardiovascular Diseases. ${ }^{7}$ Finally, although domestic-made stents consist the majority of stents used during PCI procedures, their proportion dropped significantly $(65.1 \%$ in 2013 to $61.8 \%$ in 2014), which was quite different from the scenario of dramatic increase of domestic stents used in non-military hospitals in China PEACE study during 2001-2011 (1.6\% in 2001 to $74.8 \%$ in 2011) ${ }^{6}$
In a recent meta-analysis of large, high-quality, contemporary randomised studies comparing radial and femoral access in invasively managed patients with ACS, radial access was found to reduce mortality, major adverse cardiovascular events and major bleeding. ${ }^{42}$ Similarly, with the rising adoption of radial access from 2011 to 2014 in this study, the proportion of major bleeding or haematoma after PCI and in-hospital mortality were both significantly decreased over time. In this regard, transradial access shall be advocated in countries that use it less frequently.

Compared with data reported from the NCDR in the USA during 2010-2011, ${ }^{30}$ uses of ticagrelor and bivalirudin were extremely low for patients with ACS undergoing PCI during 2011-2014 $(<3.3 \%$ and $1.0 \%$, respectively), although their proportions were rising. This might be explained by the delayed introduction of these drugs into Chinese pharmaceutical market, as well as uncovered status under the drug list of Medical Service in China. Given the great superiorities of these novel antiplatelet and anticoagulation drugs, ${ }^{143}$ coordinated advocacy efforts are needed to work with policymakers to include these drugs into the list for coverage, to improve the quality of care for patients with ACS and the outcomes of PCI procedures. Nevertheless, our data demonstrated great improvement in the quality metrics of PCI procedures during the study years. The proportion of non-obstructive CAD (stenosis <50\%) was $1.1 \%$ in 2011. Although the proportion is much higher than that reported in NCDR during 2010-2011 (0.2\%), it has dropped substantially to $0.1 \%$ in 2014 . Out study also revealed dramatic changes in the pattern of the extent of $\mathrm{CAD}$, with the dominance of three-vessel disease in 2011 $(40.4 \%)$ shifted to the dominance of one-vessel disease 
Table 4 In-hospital adverse events of patients with acute coronary syndrome (ACS) undergoing percutaneous coronary intervention (PCl) during 2011-2014

\begin{tabular}{|c|c|c|c|c|c|c|c|c|c|}
\hline & \multirow{2}{*}{\multicolumn{2}{|c|}{$\begin{array}{l}2011 \\
(n=30800)\end{array}$}} & \multirow{2}{*}{\multicolumn{2}{|c|}{$\begin{array}{l}2012 \\
(n=34974)\end{array}$}} & \multirow{2}{*}{\multicolumn{2}{|c|}{$\begin{array}{l}2013 \\
(n=39361)\end{array}$}} & \multirow{2}{*}{\multicolumn{2}{|c|}{$\begin{array}{l}2014 \\
(n=39 \text { 361) }\end{array}$}} & \multirow{3}{*}{$\begin{array}{l}\mathrm{P} \text { values } \\
\text { trend }\end{array}$} \\
\hline & & & & & & & & & \\
\hline & $\mathrm{n}$ & $\%$ & $\mathrm{n}$ & $\%$ & $\mathbf{n}$ & \%o & $\mathrm{n}$ & n \%。 & \\
\hline Complication & 496 & 16.1 & 539 & 15.4 & 429 & 10.9 & 256 & 6.5 & $<0.0001$ \\
\hline During procedure* & 342 & 11.1 & 334 & 9.5 & 269 & 6.8 & 151 & 3.8 & $<0.0001$ \\
\hline Slow flow & 201 & 6.5 & 168 & 4.8 & 159 & 4.0 & 87 & 2.2 & $<0.0001$ \\
\hline Serious dissection & 71 & 2.3 & 75 & 2.1 & 64 & 1.6 & 32 & 0.8 & $<0.0001$ \\
\hline Acute thrombosis & 54 & 1.8 & 48 & 1.4 & 36 & 0.9 & 23 & 0.6 & $<0.0001$ \\
\hline Perforation & 22 & 0.7 & 32 & 0.9 & 17 & 0.4 & 17 & 0.4 & $<0.05$ \\
\hline Cardiac tamponade & 11 & 0.4 & 17 & 0.5 & 9 & 0.2 & 7 & 0.2 & $<0.05$ \\
\hline Acute occlusion & 11 & 0.4 & 24 & 0.7 & 19 & 0.5 & 12 & 0.3 & 0.38 \\
\hline Post-procedure & 154 & 5.0 & 205 & 5.9 & 160 & 4.0 & 105 & 2.7 & $<0.0001$ \\
\hline Acute/subacute ST & 46 & 1.5 & 49 & 1.4 & 37 & 0.9 & 30 & 0.8 & $<0.001$ \\
\hline Organ failure & 37 & 1.2 & 31 & 0.9 & 29 & 0.7 & 19 & 0.5 & $<0.001$ \\
\hline Organ support & 8 & 0.3 & 2 & 0.0 & 7 & 0.2 & 3 & 0.0 & 0.15 \\
\hline Major bleeding/haematoma & 19 & 0.6 & 19 & 0.5 & 23 & 0.6 & 6 & 0.2 & $<0.01$ \\
\hline Organ bleeding & 14 & 0.5 & 21 & 0.6 & 11 & 0.3 & 11 & 0.3 & 0.06 \\
\hline Postoperative Ml & 10 & 0.3 & 20 & 0.6 & 14 & 0.4 & 7 & 0.2 & 0.10 \\
\hline Contrast reaction & 7 & 0.2 & 10 & 0.3 & 3 & 0.0 & 2 & 0.0 & $<0.01$ \\
\hline Postoperative infection & 5 & 0.2 & 6 & 0.2 & 8 & 0.2 & 3 & 0.0 & 0.40 \\
\hline Thromboembolism & 4 & 0.1 & 11 & 0.3 & 2 & 0.0 & 2 & 0.0 & $<0.05$ \\
\hline Emergent surgery & 4 & 0.1 & 2 & 0.0 & 1 & 0.0 & 2 & 0.0 & 0.18 \\
\hline Others & 28 & 0.9 & 56 & 1.6 & 43 & 1.1 & 26 & 0.7 & 0.06 \\
\hline Death & 166 & 5.4 & 179 & 5.1 & 150 & 3.8 & 113 & 2.9 & $<0.0001$ \\
\hline During PCl & 41 & 1.3 & 30 & 0.9 & 22 & 0.6 & 16 & 0.4 & $<0.0001$ \\
\hline \multicolumn{10}{|l|}{ Cardiogenic } \\
\hline Yes & 34 & 1.1 & 25 & 0.7 & 16 & 0.4 & 16 & 0.4 & $<0.0001$ \\
\hline No & 1 & 0.0 & 1 & 0.0 & 2 & 0.0 & 0 & 0.0 & 0.52 \\
\hline Uncertain & 6 & 0.2 & 4 & 0.1 & 4 & 0.1 & 0 & 0.0 & $<0.05$ \\
\hline \multicolumn{10}{|l|}{$\mathrm{PCl}$ related } \\
\hline Yes & 4 & 0.1 & 1 & 0.0 & 1 & 0.0 & 4 & 0.1 & 0.76 \\
\hline No & 23 & 0.7 & 15 & 0.4 & 11 & 0.3 & 11 & 0.3 & $<0.01$ \\
\hline Uncertain & 14 & 0.5 & 14 & 0.4 & 10 & 0.3 & 1 & 0.0 & $<0.001$ \\
\hline Post-PCl & 125 & 4.1 & 149 & 4.3 & 128 & 3.2 & 97 & 2.5 & $<0.0001$ \\
\hline \multicolumn{10}{|l|}{ Cardiogenic } \\
\hline Yes & 102 & 3.3 & 108 & 3.1 & 108 & 2.7 & 82 & 2.1 & $<0.01$ \\
\hline No & 10 & 0.3 & 22 & 0.6 & 8 & 0.2 & 9 & 0.2 & 0.08 \\
\hline Uncertain & 13 & 0.4 & 19 & 0.5 & 12 & 0.3 & 6 & 0.2 & $<0.05$ \\
\hline \multicolumn{10}{|l|}{$\mathrm{PCI}$ related } \\
\hline Yes & 4 & 0.1 & 5 & 0.1 & 7 & 0.2 & 8 & 0.2 & 0.40 \\
\hline No & 88 & 2.9 & 120 & 3.4 & 100 & 2.5 & 80 & 2.0 & $<0.01$ \\
\hline Uncertain & 33 & 1.1 & 24 & 0.7 & 21 & 0.6 & 9 & 0.2 & $<0.0001$ \\
\hline
\end{tabular}

$\mathrm{Ml}$, myocardial infarction; ST, stent thrombosis.

in $2014(37.9 \%)$ and no obvious change in two-vessel disease $(23.3 \%-24.0 \%)$. This trend was quite different with distributions found in patients undergoing PCI in the USA during 2010-2011 (38.1\%, 32.6\% and 39.1\% for one-vessel, two-vessel and three-vessel disease, respectively). ${ }^{30}$ In treated lesion vessels, although there were 


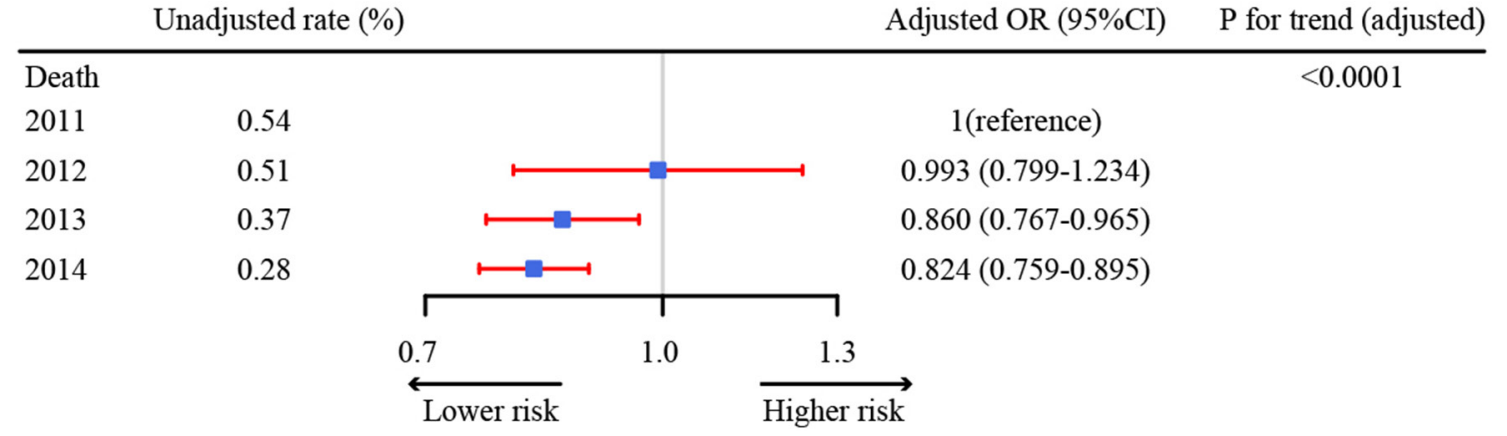

Figure 2 Adjusted in-hospital mortality for patients with acute coronary syndrome undergoing percutaneous coronary intervention. Adjusted OR of 1 shows no difference from year 2011. We included 143063 patients (30202 in 2011,34304 in 2012, 39206 in 2013 and 39351 in 2014).

remarkable increase of one-vessel disease and significant decreases of two-vessel and three-vessel diseases in proportions, interventional operators in Chinese military hospitals still treated lower proportion of one-vessel disease and higher proportion of two-vessel disease in 2014 than peers in the USA during $2010-2011(80.2 \%$ vs $86.2 \%$ and $15.0 \%$ vs $12.8 \%$, respectively). ${ }^{30}$ Of note, the proportion of treated vessels involving left main artery $(3.4 \%-4.2 \%)$ was significantly higher than proportions reported in the USA during 2010-2011 $(1.8 \%)^{21}$ as well as in Chinese non-military hospitals during 2001-2011 (0.4\%-2.1\%) in China PEACE study. ${ }^{6}$ The facts that considerable amount of grade 0-2 TIMI flow before PCI almost disappeared after PCI suggest high quality of performance of PCI procedures. Especially, compared with data in 2013, higher proportions of grade 0 and 1 TIMI flow before PCI turned to higher proportion of grade 3 TIMI flow after PCI in 2014, suggesting the quality of performance was still improving. The relatively low and decreasing rate of overall complications (1.6\% in 2011 to $0.7 \%$ in 2014) and death $(0.5 \%$ in 2011 to $0.3 \%$ in 2014$)$ for PCI procedures might be attributable to the decrease of worse cardiac function over time (patients with Killip III-IV grades decreased significantly from 2011 to 2013, online table S3). On the other hand, the consistent low rates are also suggestive of good performance of cardiac intervention on these patients.

Some limitations of this study should be noted. First, the partial revision of the registry form in 2013 has made comparisons of some critical measures impossible during 2011-2014 consecutively. However, the purpose of the necessary revision was to reflect contemporary changes in the practice of cardiac intervention during the study years. And we analysed all critical measures provided they were available. Second, due to the gigantic number of nationwide enrolled patients and limit of sufficient funding and other resources, we only compared the in-hospital outcomes for the patients. However, it is possible to follow-up the long-term outcomes for these patients, given that contact information of most patients were collected. Third, in this study comparisons of data with other studies were not matched exactly both temporally and categorically, as to the best of our knowledge, the same large-scale, nationwide registries of acute coronary syndromes during the same study period were not available. Nevertheless, we believe this study has given an updated and comprehensive overview of contemporary practice of interventional cardiology in military hospitals in China.

\section{CONCLUSION}

This study outlined the general profiles of cardiac intervention practice in contemporary military hospital in China. Our data revealed the overall interventional resources were still limited in military hospitals, with great disparities of resources and consumptions in different geographical regions across China, and major gaps still exist in optimal medical coverage for patients with ACS. Other than data from non-military hospitals, our findings can serve as an indispensable addition to a comprehensive overview of the practice of cardiac intervention in China.

Collaborators The 463 Hospital The 210 Hospital The 313 Hospital The 202 Hospital The 208 Hospital The 211 Hospital The 201 HospitalThe 205 HospitalGeneral Hospital of Jilin PAP Corps General Hospital of PLA The Affiliated Hospital of PAP College of Logistics Bethune International Peace Hospital General Hospital of PAP The 252 Hospital General Hospital of Navy The 304 Hospital The 254 Hospital The 309 Hospital The General Hospital of Beijing Military Region The Second Artillery General Hospital General Hospital of Air Force The 305 Hospital The 306 Hospital The 307 Hospital The 264 Hospital The 261 Hospital The 251 Hospital The 263 Hospital The 285 Hospital The 464 Hospital The Second Hospital of Beijing PAP Corps General Hospital of Beijing PAP Corps General Hospital of Hebei PAP Corps General Hospital of Shanxi PAP Corps Changhai Hospital of SMMU General Hospital of Nanjing Military Region General Hospital of Jinan Military Region Changzheng Hospital of SMMU The 88 Hospital The 148 Hospital The 105 Hospital The 401 Hospital The 97 Hospital Fuzhou General Hospital of PLA Anqing Hospital of Navy The 101 Hospital The 89 Hospital The 107 Hospital The 171 Hospital The 404 Hospital The 94 Hospital The 411 Hospital The 174 Hospital The 180 Hospital The 85 Hospital The 98 Hospital The 117 Hospital General Hospital of Zhejiang PAP Corps The 123 Hospital The 175 Hospital The 456 Hospital The 92 Hospital General Hospital of Fujian PAP Corps General Hospital of Guangzhou Military Region The 181 Hospital The 303 Hospital The 458 Hospital The 163 Hospital The 169 Hospital General Hospital of Guangdong PAP Corps General Hospital of Hunan PAP Corps The 425 Hospital The 187 Hospital The 422 Hospital The 425 Hospital Hainan Hospital of General Hospital of PLA Wuhan General Hospital of PLA The 150 Hospital The 91 Hospital The 153 Hospital The 371 Hospital General Hospital of Henan PAP Corps The 152 Hospital The 155 Hospital The 161 Hospital The 159 Hospital General Hospital of Hubei PAP Corps The 477 Hospital Xijing Hospital of FMMU Tangdu Hospital of FMMU General Hospital of Lanzhou Military Region Urumchi 
General Hospital of PLA General Hospital of Shannxi PAP Corps The 451 Hospital The 3 Hospital The 474 Hospital The 323 Hospital The 273 Hospital The 18 Hospital General Hospital of Ningxia PAP Corps General Hospital of Xinjiang PAP Corps The 1 Hospital Kunming General Hospital of PLA Xinqiao Hospital of TMMU Southwest Hospital of TMMU Daping Hospital of TMMU The General Hospital of Chengdu Military Region The 452 Hospital The 59 Hospital Tibet General Hospital of PLA The 324 Hospital The 37 Hospital The 44 Hospital Chengdu Hospital of Sichuan PAP Corps General Hospital of Sichuan PAP Corps Leshan Hospital of Sichuan PAP Corps

Contributors RZ participated in the data collection an drafted the manuscript. $\mathrm{KX}$ participated in the data collection and design of the study. YL, QM and YH participated in the design of the study and undertook statistical analyses. All authors were involved in writing the paper and had final approval of the submitted and published versions.

Funding The NRCIMH program was supported by the Ministry of Health of the General Logistics Department of PLA. This study was spported by National Key Research and Development program of China (grant number: 2016YFC1301300). $\mathrm{RZ}$ is funded by a project grant from the Liaoning Office of Science and Technology of China (Shenyang, China, No. 20170540928).

Competing interests None declared.

Patient consent Not required.

Ethics approval This study was approved by the ethics committee of the General Hospital of Shenyang Military Region. The requirement of informed consent was waived due to the nature of the retrospective study. All participating hospitals accepted the ethics committee approval.

Provenance and peer review Not commissioned; externally peer reviewed.

Data sharing statement № additional data are available.

Open access This is an open access article distributed in accordance with the Creative Commons Attribution Non Commercial (CC BY-NC 4.0) license, which permits others to distribute, remix, adapt, build upon this work non-commercially, and license their derivative works on different terms, provided the original work is properly cited, appropriate credit is given, any changes made indicated, and the use is non-commercial. See: http://creativecommons.org/licenses/by-nc/4.0/.

\section{REFERENCES}

1. Han Y, Guo J, Zheng Y, et al. Bivalirudin vs heparin with or without tirofiban during primary percutaneous coronary intervention in acute myocardial infarction: the BRIGHT randomized clinical trial. JAMA 2015;313:1336-46.

2. Li Y, Gu J, Zhou J, et al. The epidemiology of traumatic brain injury in civilian inpatients of Chinese Military Hospitals, 2001-2007. Brain Inj 2015;29(7-8):981-8.

3. Xu JH, Qiu J, Zhou JH, et al. Pediatric burns in military hospitals of China from 2001 to 2007: a retrospective study. Burns 2014;40:1780-8.

4. Zhu XY, Zhang DZ. Investigation Team of Military Structural Heart Disease Intervention. [Interventional therapy for structural heart diseases in People's Liberation Army hospitals between 2005 and 2006]. Zhonghua Xin Xue Guan Bing Za Zhi 2008;36:608-12.

5. Anon. Rankings of Top Hospitals and Top Specialties in China: Reports from the Institute of Hospital Administration of Fudan University [in Chinese] 2009-2015. http://www.fudanmed.com/ institute/news222.aspx\#/ (accessed 22 Mar 2018).

6. Zheng X, Curtis JP, Hu S, et al. Coronary catheterization and percutaneous coronary intervention in China: 10-year results from the China PEACE-Retrospective CathPCI Study. JAMA Intern Med 2016;176:512-21.

7. Yao TM, Chen SL, Bai SY, et al. Establishment of quality control system for Angiocardiopathy Interventional Therapy in Military Hospitals [in Chinese]. Hosp Adm J Chin PLA 2014;21:133-4.

8. The initiation of facilitated authentication of China Chest Pain Centers [in Chinese].. http://www.chinacpc.org/home/aview/22 (acessed 30 Jun 2018).

9. Sun Y, Xu K, Jiang TM, et al. Relationship between the degree of target vessel occlusion and the in-hospital mortality in patients with acute ST-elevated myocardial infarction [in Chinese]. Med J Chin PLA 2016:6:456-60.

10. Bao D, Xu K, Quu J, et al. Effect of gender on in-hospital mortality in patients with acute ST-elevation myocardial infarction undergoing primary percutaneous coronary intervention [in Chinese]. Med J Chin PLA 2016;41:446-51.
11. Zhao R, Xu K, Sun Y, et al. Characteristics of STEMI patients undergoing primary $\mathrm{PCl}$ with different medical insurance coverage from the database of cardiovascular intervention diagnosis and treatment of PLA [in Chinese]. Chin J Health Care Med 2016;18.

12. China Society of Cardiology of Chinese Medical Association. Editorial Board of Chinese Journal of Cardiology. Guideline for diagnosis and treatment of patients with unstable angina and non-ST-elevation myocardial infarction [in Chinese]. Zhonghua Xin Xue Guan Bing Za Zhi 2007;35:295-304.

13. China Society of Cardiology of Chinese Medical Association. Editorial Board of Chinese Journal of Cardiology. Guideline for diagnosis and treatment of patients with ST-elevation myocardial infarction [in Chinese]. Zhonghua Xin Xue Guan Bing Za Zhi 2010;38:675-90.

14. Wright RS, Anderson JL, Adams CD, et al. 2011 ACCF/AHA Focused Update of the Guidelines for the Management of Patients With Unstable Angina/ Non-ST-Elevation Myocardial Infarction (Updating the 2007 Guideline): a report of the American College of Cardiology Foundation/American Heart Association Task Force on Practice Guidelines. Circulation 2011;123:2022-60.

15. Antman EM, Hand M, Armstrong PW, et al. 2007 Focused Update of the ACC/AHA 2004 Guidelines for the Management of Patients With ST-Elevation Myocardial Infarction: a report of the American College of Cardiology/American Heart Association Task Force on Practice Guidelines: developed in collaboration With the Canadian Cardiovascular Society endorsed by the American Academy of Family Physicians: 2007 Writing Group to Review New Evidence and Update the ACC/AHA 2004 Guidelines for the Management of Patients With ST-Elevation Myocardial Infarction, Writing on Behalf of the 2004 Writing Committee. Circulation 2008;117:296-329.

16. Gibson CM, Cannon CP, Daley WL, et al. TIMI frame count: a quantitative method of assessing coronary artery flow. Circulation 1996;93:879-88.

17. Cutlip DE, Windecker S, Mehran R, et al. Clinical end points in coronary stent trials: a case for standardized definitions. Circulation 2007;115:2344-51.

18. Thygesen K, Alpert JS, White HD. Joint ESC/ACCF/AHA/WHF Task Force for the Redefinition of Myocardial Infarction. Universal definition of myocardial infarction. Eur Heart J 2007;28:2525-38.

19. Masoudi FA, Ponirakis A, de Lemos JA, et al. Trends in U.S. Cardiovascular care: 2016 report from 4 ACC National cardiovascular data registries. J Am Coll Cardiol 2017;69:1427-50.

20. Guo Y, Barnett AG, Pan X, et al. The impact of temperature on mortality in Tianjin, China: a case-crossover design with a distributed lag nonlinear model. Environ Health Perspect 2011;119:1719-25.

21. Tian Z, Li S, Zhang J, et al. Ambient temperature and coronary heart disease mortality in Beijing, China: a time series study. Environ Health 2012;11:11-56.

22. Yang L, Li L, Lewington S, et al. Outdoor temperature, blood pressure, and cardiovascular disease mortality among 23000 individuals with diagnosed cardiovascular diseases from China. Eur Heart J 2015;36:1178-85

23. Jin $Y$, Hou Z, Zhang D. Determinants of health insurance coverage among people aged 45 and over in china: who buys public, private and multiple insurance. PLoS One 2016;11:e0161774.

24. Marten R, Mclntyre D, Travassos C, et al. An assessment of progress towards universal health coverage in Brazil, Russia, India, China, and South Africa (BRICS). The Lancet 2014;384:2164-71.

25. Shi L, Zhang D. China's new rural cooperative medical scheme and underutilization of medical care among adults over 45: evidence from CHARLS pilot data. J Rural Health 2013;29(s1):s51-61.

26. Ben-Yehuda O, Kazi DS, Bonafede M, et al. Angina and associated healthcare costs following percutaneous coronary intervention: A real-world analysis from a multi-payer database. Catheter Cardiovasc Interv 2016;88:1017-24.

27. Hyun KK, Essue BM, Woodward M, et al. The household economic burden for acute coronary syndrome survivors in Australia. BMC Health Serv Res 2016;16:636.

28. Kim J, Lee E, Lee T, et al. Economic burden of acute coronary syndrome in South Korea: a national survey. BMC Cardiovasc Disord 2013;13:55.

29. Argacha JF, Collart $P$, Wauters $A$, et al. Air pollution and ST-elevation myocardial infarction: a case-crossover study of the Belgian STEMI registry 2009-2013. Int J Cardiol 2016;223:300-5.

30. Dehmer GJ, Weaver D, Roe MT, et al. A contemporary view of diagnostic cardiac catheterization and percutaneous coronary intervention in the United States: a report from the CathPCI Registry of the National Cardiovascular Data Registry, 2010 through June 2011. J Am Coll Cardiol 2012;60:2017-31.

31. O'Gara PT, Kushner FG, Ascheim DD, et al. 2013 ACCF/AHA guideline for the management of ST-elevation myocardial infarction: a report of the American College of Cardiology Foundation/American 
Heart Association Task Force on Practice Guidelines. Circulation 2013;127:529-55.

32. Bradley EH, Nallamothu BK, Stern AF, et al. The door-to-balloon alliance for quality: who joins national collaborative efforts and why? Jt Comm J Qual Patient Saf 2009;35:93-9.

33. Armstrong PW, Boden WE. Reperfusion paradox in ST-segment elevation myocardial infarction. Ann Intern Med 2011;155:389-91.

34. Bates ER, Nallamothu BK. Commentary: the role of percutaneous coronary intervention in ST-segment-elevation myocardial infarction. Circulation 2008;118:567-73.

35. Henry TD, Sharkey SW, Burke MN, et al. A regional system to provide timely access to percutaneous coronary intervention for ST-elevation myocardial infarction. Circulation 2007:116:721-8.

36. Jollis JG, Roettig ML, Aluko AO, et al. Implementation of a statewide system for coronary reperfusion for ST-segment elevation myocardia infarction. JAMA 2007;298:2371-80.

37. Jacobs AK. Primary percutaneous coronary intervention without cardiac surgery on-site: coming to a hospital near you? Am Heart $J$ 2008;155:585-8.
38. Jollis JG, Mehta RH, Roettig ML, et al. Reperfusion of acute myocardial infarction in North Carolina emergency departments (RACE): study design. Am Heart J 2006;152:851.e1-851.e11.

39. Kalla K, Christ G, Karnik R, et al. Implementation of quidelines improves the standard of care: the Viennese registry on reperfusion strategies in ST-elevation myocardial infarction (Vienna STEMI registry). Circulation 2006;113:2398-405.

40. Rokos IC, Larson DM, Henry TD, et al. Rationale for establishing regional ST-elevation myocardial infarction receiving center (SRC) networks. Am Heart J 2006;152:661-7.

41. Ting HH, Rihal CS, Gersh BJ, et al. Regional systems of care to optimize timeliness of reperfusion therapy for ST-elevation myocardial infarction: the Mayo Clinic STEMI Protocol. Circulation 2007;116:729-36.

42. Andò G, Capodanno D. Radial versus femoral access in invasively managed patients with acute coronary syndrome. Ann Intern Med 2015;163:932-40.

43. Wallentin L, Becker RC, Budaj A, et al. Ticagrelor versus clopidogrel in patients with acute coronary syndromes. $N$ Engl J Med 2009;361:1045-57. 